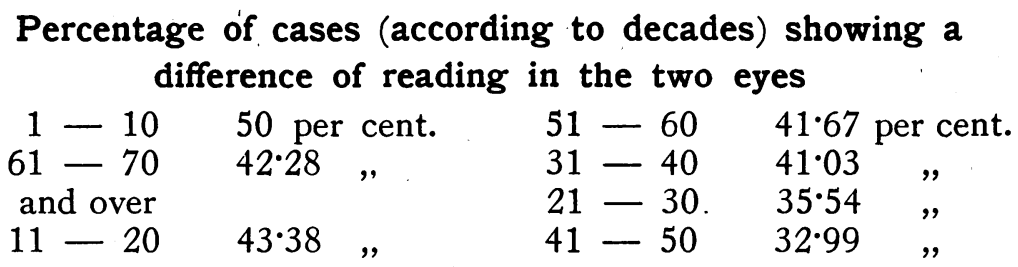

Average differences according to decades

$\begin{array}{llrr}51-60 & 3 \cdot 41 & 21-30 & 2 \cdot 35 \\ 61-70 & 3 \cdot 04 & 11-20 & 2 \cdot 11 \\ \text { and over } & & 1=10 & 2 \cdot 4 \\ 41-50 & 2 \cdot 59 & 31-40 & 2 \cdot 02\end{array}$

\title{
A NEW OPERATION FOR PTOSIS
}

BY

\author{
ERnest E. Maddox, M.D., F.R.C.S.ED. \\ BOURNEMOUTH, ENGLAND.
}

I HAVE practised, during the last four or five years, an operation' for ptosis which, in suitable cases, has yielded so much more pleasing results than those I have ever been able to obtain by former methods, that a description of it may perhaps be justified.

Few will dispute that ptosis operations, however successful they may be reckoned surgically, rarely quite realize an artist's ideal from the æsthetic point of view. Gratifying immediate results, it is true, are obtained from artificial tendons, but a very natural prejudice exists against foreign bodies left in the organism. Strange to say, with the exception of Wray's punctures (for slight ptosis), and the little practised Motais group of operations, nearly all the procedures advocated in the present day, attack the tendon from the skin side, which mode of approach must, in itself, make for æsthetic loss, owing to the derangement of so many important structures, namely:

(1) The skin, whose natural folds cannot be disarranged without impairment of symmetry and beauty.

(2) The areolar tissue, which never recovers its original lissomeness after operative interference.

(3) The orbicularis muscle, which like all other muscles, acts best in the state of nature.

(4) The orbital fascia, which, being the suspensory ligament of the eyelid, is not improved by a large hole made in it.

(5) The numerous delicate strands which the levator tendon gives off to the skin, and of which many cannot fail to be severed or damaged.

Contrast with this the simplicity of approach from behind, after the precedent set, about the year 1858, by Sir William Bowman. 
After double eversion of the eyelid, nothing intervenes between the surgeon and the tendon but a thin loose layer of that peculiarly accommodating membrane, the conjunctiva, which is no sooner divided along the upper margin of the tarsus and reflected from the tendon, than the latter lies in full view, and can be shortened without interfering at all with the natural beauty of the front of the eyelid.

Why, then, has Sir William Bowman's operation practically dropped out of use? Firstly, I think, because its procedure has been found a little too difficult, and, secondly, because the excision of a large piece of the tendon left the door open for possible disaster if the sutures should cut out and allow the lid to droop worse than ever. Moreover, it is impossible to excise the tendon without some impairment of the delicate structures connected with its anterior surface. It may be interesting at this point to quote the exact description of Sir William Bowman's operation from the first volume of the Royal London Ophthalmic Hospital Reports, where we read: "In one case . . . . Mr. Bowman applied a new planhe everted the lid and excised the posterior or upper edge of the palpebral cartilage, with about half an inch of the tendon of the levator palpebræ inserted into it. Before the actual removal of the piece, very fine threads were passed so as to bring together the edges, and thus secure a shortening of the tendon of the levator muscle, to the extent of three quarters of an inch."

The operation to be described agrees with Sir William Bowman's in approaching the tendon from behind, but differs in that it does not involve excision of the tendon. There is no hazard, therefore, connected with the cutting out of sutures, neither are the structures connected with the anterior face of the tendon interfered with, as when the tendon is itself removed.

The procedure grew out of an interesting series of experiments to shorten tendons in general, on a principle which might be called that of " supported cauterization,"- that is to say, by streaking the bare surface of a tendon, to about half its depth, by narrow linear grooves, parallel with the fibres, and by then supporting the tendon with sutures to prevent it from stretching while the cicatrices are still young and tender.

Any application of heat impairs the vitality of living tissue for a certain time, and with impairment of its vitality, is lost its vital elasticity, so that in the case of an ocular tendon the natural tension of the muscle would stretch the weakened fibres during the first fortnight or so were no provision made for support. My experiences with the other ocular tendons are not yet so complete as with the levator, in which latter they have now been watched for a sufficient number of years to let me speak with confidence.

For the posterior operation under present consideration, the 
only special instrument required (and that is more convenient than essential) is made easily by soldering an oval strip of metal transversely on to the tip of one leg of the ordinary fine mouse-toothed conjunctival forceps, made with a clasp, as shown in Fig. 1, and so as to extend about seven millimetres beyond the teeth.

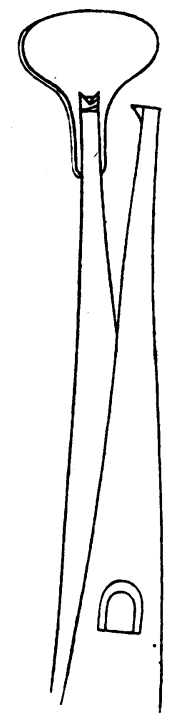

Fig. 1.

FIG. 1. Addition to clasped conjunctival forceps.

Other instruments advisable are fine conjunctival forceps, Stevens's curved scissors, narrow! Graefe knife, fine clasped forceps with curved extremities for gripping the tendon, three double-armed sutures of No. 1 silk, or a little stouter, greased with carbolised vaseline, a needle holder, and two fine black conjunctival sutures.

The sutures are placed in carbolic, 1 in 40 ; and gauze wetted in the same solution is laid on the cheek and brow, after the usual sterilisation of the eye and lids. Adrenalised cocain affords ample anæsthesia, though for very young or nervous patients general anæsthesia is preferable.

After effecting the first ordinary eversion of the lid, the second eversion is made by grasping the extreme apex of the tarsus with the lid evertor, so that the metal plate shall lie against the tarsus, which is then everted the second time, and maintained in position by the weight of the instrument as it lies upon the brow. The whole field of operation thus lies fully exposed. The conjunctiva is now divided along the upper margin of the tarsus. This is most easily done by transfixion with a narrow Graefe knife, after which a pair of scissors reflects the conjunctiva from the tendon so as to leave it 
fully bared. Its fibres are then seared, with an electro-cautery, in longitudinal furrows from the tarsus to as high up as the case requires.

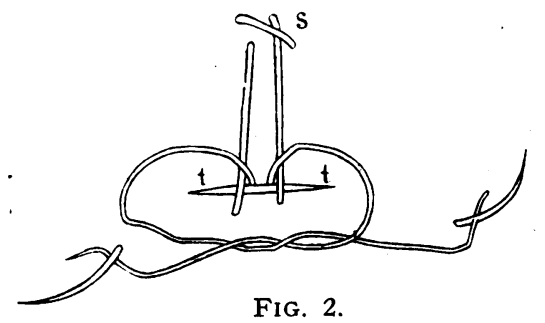

FIG. 2. Central suture before being tied. $S$, double turn in tendon. $t, t$, cut edge of tarsus.

The centre of the tendon, a little higher up still, is now grasped in fine locking fixation forceps, made preferably with slightly curved ends, so that one needle of a double-armed suture can be passed through the gripped portion of the tendon rather deeply, twice over in the same direction so as to include a bundle of the tendon fibres in a ring of thread, shown in Fig. 2, which tightens as the ends of the suture are pulled on. It would, of course, be imprudent to tie this in a knot because of the impossibility then of removing it after healing. Two similar sutures are placed on either side of the first, though even without their aid a good result is sometimes easily obtainable by the first suture alone. Their only object is to maintain the symmetry of the lid. Next, the apex of the tarsus is to be snipped off with scissors (though for a small effect this can be dispensed with), and the two needles of the central suture, either with or without an intermediate dip into the tendon, are passed solidly through the tarsus side by side, not too near its cut edge, from the conjunctival surface to the deep surface, and the needles brought out between the parallel threads (as in Fig. 2), so that the knot, when the suture is tied, shall be sunk behind the upper edge of the tarsus without touching the cornea. Before tying, however, the two lateral sutures are passed through the tarsus similarly, and then all are knotted. Two or three fine sutures to replace the conjunctiva complete the operation.

The use of the lid evertor makes the operation extremely easy of performance, though with the slight penalty that the immediate result is not always so good as the remote one (herein differing from most ptosis operations), owing to the stretching of the levator muscle. When desirable to avoid stretching, it is necessary to dispense with the lid evertor, and work more or less in a cavity, into which a small electric light must be kept shining.

In any case the sutures should be left undisturbed for two, or preferably three, weeks, when their withdrawal is quite easy. It 
should be effected, however, with as little stretching of the tendon as possible. The natural wrinkles in the skin of the lid should be found not altered, but merely accentuated. The greater the power left in the levator, the greater the success of this operation, and time does not appear to lessen its eftect. On the contrary, though the natural wrinkles of the skin display themselves quite prettily, the full effect of the operation is sometimes not obtained for three or four months. Herein it differs from those in which the effect begins at once to diminish. Perhaps the stretching takes some months to be recovered from, or it may be that the cicatricial contraction continues. $\mathrm{Be}$ this as it may, the final result is generally very pleasing, as I have proved in patients as young as five years and as old as seventy. The operation does some good in nearly all kinds of ptosis, but most, of course, when the tendon is well developed and the muscle not too completely paralysed. Not having yet applied "supported cauterization" to the tendon on the skin side, or to the suspensory ligament of the lid, I can say nothing about its merits, if any.

No purely posterior operation is, of course, available in the congenital absence of a levator, but in acquired ptosis it always does some good, since even if the levator be completely paralysed, the mere elasticity of the tissues working against the orbicularis counts for something. A posterior operation can, if necessary, be supplemented by an anterior one, such as Pagenstecher's sutures, to bring the frontalis into play as well.

The oft-given caution need scarcely be reiterated that before undertaking any operation for complete ptosis, care should be exercised that troublesome diplopia shall not follow the uncovering of the pupil.

\section{ON MACULAR PERCEPTION IN ADVANCED CATARACT}

BY

\section{GEORGe Young,}

OPHTHALMIC SURGEON TO THE ESSEX COUNTY HOSPITAL, COLCHESTER.

Is the macula sound? A daily question in mature senile cataract. Our senses being nearly useless, experience guides us in deciding whether to operate or not. Macular disease occasionally eludes the most alert; inexpressibly aggravating are the consequences. Hoping to elicit something better, I venture to submit two methods which, at most, prognosticate a healthy macula.

For many years I placed a well centred, perforated disc in front of the test eye, the other being excluded. With a fine needle a hole, $0.2 \mathrm{~mm}$., is easily made in a thin blackened card. 